\title{
The Association between Mobile Phone Use and Severe Traffic Injuries: A Case-Control Study from Saudi Arabia
}

\author{
Suliman Alghnam ${ }^{1, *}$, Jawaher Towhari ${ }^{2}$, Mohamed Alkelya ${ }^{3}{ }^{\circledR}$, Ahmad Alsaif ${ }^{4}$, \\ Mohamed Alrowaily ${ }^{4}$, Fawaz Alrabeeah ${ }^{5}$ and Ibrahim Albabtain ${ }^{6}$ \\ 1 Population Health Section-King Abdullah International Medical Research Centre (KAIMRC), \\ King Saud Bin Abdulaziz University for Health Sciences (KSAU-HS), Riyadh 11426, Saudi Arabia \\ 2 College of Medicine, King Saud bin Abdulaziz University for Health Sciences, Riyadh 11426, Saudi Arabia \\ 3 Health Research Department, Saudi Health Council, Riyadh, 13315, Saudi Arabia \\ 4 Community Medicine Department, King Khalid University Hospital, Riyadh 12372, Saudi Arabia \\ 5 King Abdulaziz Medical City, National Guard Healthcare Affairs, Riyadh 11426, Saudi Arabia \\ 6 Department of Surgery, King Abdulaziz Medical City, National Guard Healthcare Affairs, \\ Riyadh 11426, Saudi Arabia \\ * Correspondence: Ghnams@ngha.med.sa; Tel.: +966-(11)-429-4383
}

Received: 6 May 2019; Accepted: 24 July 2019; Published: 29 July 2019

\begin{abstract}
Road traffic injury (RTI) is the third leading cause of death in Saudi Arabia. Using a mobile phone when driving is associated with distracted driving, which may result in RTIs. Because of limited empirical data, we investigated the association between mobile phone use and RTI in injured patients and community controls in Riyadh. Cases were patients admitted to King Abdulaziz Medical City (KAMC) between October 2016 and March 2018 due to RTIs. During admission, mobile phone use at the time of the accident was investigated. The controls were drivers observed at various locations citywide. A logistic regression model was constructed to estimate the association between mobile phone use while driving and sustaining RTIs. We included 318 cases and 1700 controls. For the cases, using a mobile phone was associated with higher severity and prevalence of disability. In addition, using a mobile phone while driving is associated with $44 \%$ higher odds of incurring a severe RTI $(p=0.04)$. Mobile phone use while driving is prevalent in Riyadh and pose a significant threat of disability. In addition, the low prevalence of seatbelt use is alarming and requires significant improvement. Prevention programs may use these findings to educate the public and policymakers and to advocate for increased visibility of enforcement to reduce RTIs and improve population health.
\end{abstract}

Keywords: road injuries; mobile phone; seatbelt; HRQOL; Saudi Arabia

\section{Introduction}

Traffic accidents are a significant threat to public health in every country. Globally, as many as 50 million individuals sustain a road traffic injury (RTI) every year [1]. From a financial perspective, the estimated global cost of RTIs is approximately $\$ 518$ billion, of which more than $\$ 65$ billion is spent in developing countries [2].

In Saudi Arabia (SA), RTI is the third leading cause of death and the leading cause of years of life lost (YLLs) [3]. According to the World Health Organization, SA has a traffic mortality rate of 24.8 per 100,000, which is substantially higher than other countries (i.e., Qatar: 14 per 100,000) with a similar demographic profile and driving environment [4]. Notably, RTIs account for over $80 \%$ of all trauma admissions, and at any moment, $20 \%$ of hospital beds are occupied by RTI patients $[5,6]$. While the burden of RTIs is decreasing in developed countries, it is increasing in developing countries such as SA. 
In 2016, there was an $8 \%$ increase in mortality compared to the preceding year [7]. Evidently, traffic accidents pose a significant burden on population health.

Several factors contribute to the incidence of RTIs [8,9]. These may include suboptimal road conditions, unsafe motor vehicles, and risky driving behaviors [10]. Speeding, running a red light, driving under the influence, seatbelt nonuse, and distracted driving are examples of common traffic violations associated with RTIs globally and in SA [11]. Research quantifying the contribution of these risk factors may facilitate planning preventative strategies.

Distracted driving is an emerging threat to traffic safety [12]. There are many forms of distraction, including manual, visual, auditory, or cognitive [13]. For example, drivers can be distracted visually by looking away from the road, or physically by holding or using devices such as mobile phones [14]. Globally, there is an increased risk of RTIs due to distracted driving associated with mobile phone use [15-17]. The use of mobile phones while driving has been linked to a slower reaction time, less control, and less attention to relevant visual information [18]. The increased use of smartphones and engagement in social media may also have contributed to increasing distracted driving and, consequently, the incidence and severity of RTIs [19].

Literature from developed countries report that using a mobile phone while driving is associated with an increased risk of traffic accidents. However, these results may not necessarily apply to the Saudi population [20]. The prevalence of mobile phone use while driving may vary from one country to another due to differences in driving environments or behaviors. Literature suggests that aggressive and risk-taking behavior is prevalent among Saudi drivers [21].

There is a paucity of empirical data about mobile phone use while driving in SA. Previous local studies were based on self-report surveys among the general population focusing on habitual use [22-24]. Concurrent with increased mobile phone subscriptions in recent years, a recent study found an increase in RTI severity beginning in 2014, possibly due to distracted driving [25]. There is a need to fully understand the impact of mobile phone use while driving on traffic safety in SA to guide policy development and facilitate effective prevention.

Though it is known that thousands of individuals die annually in SA due to RTIs, the impact on survivors is under-researched. Specifically, to what extent does RTIs affect health-related quality of life (HRQOL) of individuals who survived an RTI? In addition, to our best knowledge, no previous studies investigated the association between mobile phone-related RTIs and health outcomes. Police traffic accident reports do not include information about mobile phone use or other relevant factors such as seatbelt use that may play a role in RTIs and their outcomes. In addition, the information may not have been captured accurately. A study reported that police underestimate annual deaths due to traffic accidents [26]. Obtaining information about mobile phone and seatbelt use from survivors could be a starting point to evaluate their impact on RTIs.

Evaluating the HRQOL of injured patients may provide a basis to determine the burden of non-fatal injuries in SA. The results could also offer an opportunity to compare decrements following an RTI with other countries, as well as an evidence-base for interventions to improve the health of those affected. Therefore, our study aims to (1) evaluate the association between mobile phone use and RTI, and (2) assess the HRQOL of individuals who sustained an RTI. We hypothesize that mobile phone use is associated with an increased risk and severity of RTIs, leading to poor health outcomes.

\section{Methods}

This is an observational case-control study involving two groups: Injured and non-injured populations.

\subsection{Injured Population (Cases)}

Cases were obtained from King Abdulaziz Medical City (KAMC) in Riyadh, the capital of SA. KAMC is equipped to treat complex injuries and has access to specialized teams including general, vascular, and orthopedic surgeons. We identified patients who were captured in the hospital's trauma registry, which has been collecting trauma admission data since 2001. The registry captures any trauma 
related admission as well as those who died during or prior to hospitalization. Participants were recruited from KAMC inpatient wards following admission via the emergency department. Patients were included if they sustained non-fatal RTIs as drivers or front seat passengers and were admitted to the hospital. Patients intubated for more than two weeks were excluded due to the inability to obtain their seatbelt and mobile phone use information.

\subsection{Non-Injured (Controls)}

Four observers worked in pairs to observe vehicles at various highway overpasses and inner-city intersections in Riyadh (Figure 1). Four major highways, where significant traffic flow exists, were selected: The roads connecting Riyadh to the northern, southern, eastern, and western regions of SA. Data collection was done during weekdays in the late afternoon rush hour (between 15:00 and 18:00). For each of the four locations, 200 vehicles were observed. To record the study information and ensure safety while collecting highway data, observers stood on the sidewalks of highway overpasses. Data collection started when observers announced that they will observe the third vehicle passing their way. When selecting the vehicle, the observers specified some of the vehicle's features (i.e., color) before documenting the driver's seatbelt and mobile phone use.

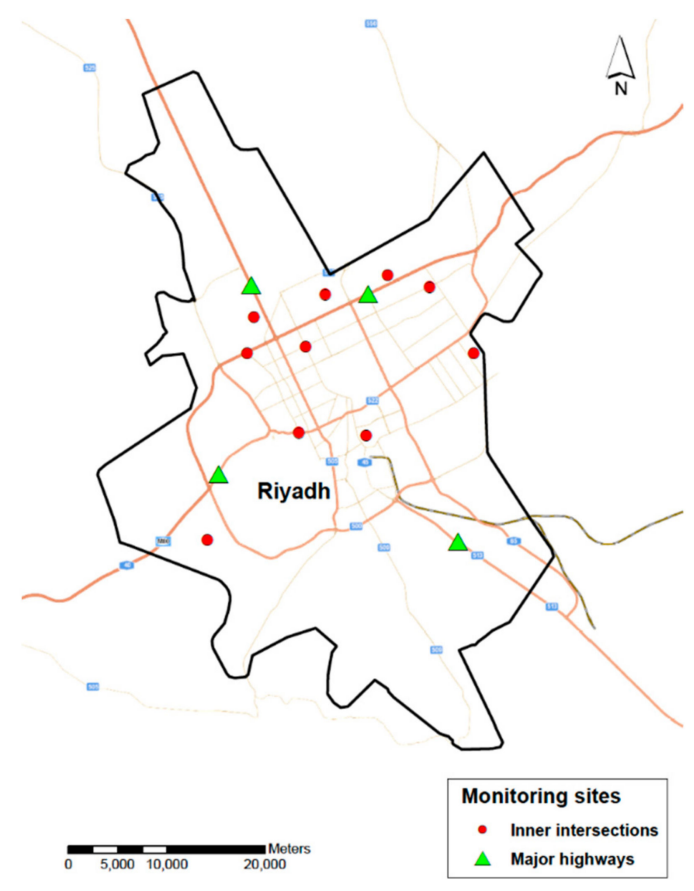

Figure 1. Observation sites for seatbelt and mobile violations in Riyadh.

Riyadh can be divided into nine main zones, separated by four major highways. Ten intersections were selected within each zone. Next, using computer randomization, one intersection was selected from each zone. The observers stood at a corner at each of the nine intersections where it was possible to clearly and safely inspect passing vehicles from all directions. One hundred vehicles were observed for seatbelt and mobile phone use while driving through the intersection.

To ensure accuracy of data collection, the observers stood on an elevated pedestrian overpass that allowed observing vehicles from a reasonable distance and the ability to gaze into each vehicle. For inner city intersections, the velocity of the vehicles was slow enough for the observers to record their data. All collected data were evaluated using the Kappa statistic to ensure validity and precision. There was substantial agreement between the two observers ranging from 0.70 for mobile phone use to 0.83 in seatbelt use. One observer was selected at random and used for all analyses in this study. The data used for the controls was part of a project estimating the baseline prevalence of seatbelt and mobile use of drivers in Riyadh [27]. 


\subsection{Outcome Measures}

The primary outcome measure was using a mobile phone while driving for both cases and controls. More specifically, mobile phone use was defined as usage while driving, including holding it to the ear or holding the device to text, dial, or taking photographs. Data regarding seatbelt use was also collected.

The secondary outcome was the European Quality of Life Measure, EQ-5D [28]. This measure was used to assess disability in injured patients. EQ-5D is a self-reported health measure covering five dimensions: Mobility, pain/discomfort, self-care, usual activity, and depression/anxiety. Each dimension was measured by answering a five-level response. Disability was defined as reporting "moderate" or "severe" limitation in any of the five domains.

The EQ-5D also includes the EuroQol visual analog scale (EQ-VAS), which requires respondents to rate their current health on a scale ranging from 0 , worst possible health, to a 100 , the best possible health.

\subsection{Data Collection}

Research coordinators administered the EQ-5D in Arabic, validated in previous studies [29,30]. Two interviewers collected data from participants after obtaining informed consent. The data collected included seatbelt nonuse (driver or passenger), mobile phone use (of the driver) at the time of the accident, as well as socio-demographic and pre-injury characteristics of the participants.

\subsection{Sample Size}

Because this was a case-control study, the sample calculation was based on the following criteria: (1) power of $90 \%$; (2) a case-control ratio of 1:5 (five controls for each case); (3) an alpha of 5\%; (4) prior prevalence of mobile phone use of $53.9 \%$ estimated by Osuagwu et al. and a confidence level of 95; and (5) a least extreme odds ratio to be detected as 1.5 [24]. The estimated required sample size was 1904 subjects: 318 cases (patients) and 1586 controls.

\subsection{Statistical Analysis}

STATA version 15 for Mac (STATA Corp., College Station, TX, USA) was used for all statistical analyses. For cases, descriptive statistics for age, sex, mechanism of injury, transfer mode, Injury Severity Score (ISS), and other clinical or healthcare utilization variables were compared to mobile use status. Means were compared for continuous variables and proportions for categorical variables using Student's $t$ and Chi-square tests, respectively. To investigate the association between mobile phone use and health outcomes, the prevalence of disability in the EQ-5D domains was compared with mobile phone use status. Disability was defined as a "severe" or "moderate" problem in any of the EQ-5D domains.

For both cases and controls, the prevalence of seatbelt and mobile phone use was calculated with a 95\% confidence interval. The association between mobile phone use and RTIs was determined using a simple logistic regression technique. Because the data from the cases included missing values, we performed the analysis using multiple imputation procedures to evaluate if the missing value could have influenced the findings. A $p$-value of 0.05 or lower was used as a cut-off for statistical significance. The study was reviewed and approved by the Institutional Review Board at King Abdullah International Research Center (KAIMRC).

\section{Results}

Of the 2018 participants included, 318 were cases, and 1700 were controls. Cases, overall, were relatively young (mean age 29.1 years, Table 1 ) and mostly male (86\%). A fifth of the cases, $71(22.5 \%)$, reported that they do not know or remember whether a mobile phone was involved in the crash. Of the remaining, $17.2 \%$ sustained RTIs while a mobile phone was used. 
Table 1. Descriptive characteristics of cases admitted at King Abdulaziz Medical City, 2017-2018.

\begin{tabular}{|c|c|c|c|c|}
\hline Variable & $\begin{array}{l}\text { Mobile Phone Used } \\
\qquad N=42\end{array}$ & $\begin{array}{l}\text { No Mobile Phone Used } \\
\qquad N=202\end{array}$ & $\begin{array}{c}\text { Total Population } \\
\quad N=247\end{array}$ & $p$-Value \\
\hline Mean age & 27.37 & 31.72 & 29.34 & $0.12^{\wedge}$ \\
\hline Male \% & 90.48 & 85.15 & 86.07 & $0.82 *$ \\
\hline \multicolumn{5}{|l|}{ Mechanism of injury \% } \\
\hline Occupant & 26.19 & 35.64 & 34.02 & \multirow{2}{*}{$0.23 *$} \\
\hline Driver & 73.81 & 64.36 & 65.98 & \\
\hline \multicolumn{5}{|l|}{ Transport to hospital \% } \\
\hline EMS & 82.93 & 63.02 & 66.52 & \multirow{2}{*}{$0.01 *$} \\
\hline Private vehicle & 17.07 & 36.98 & 33.48 & \\
\hline $\begin{array}{l}\text { Pre-injury reported health } \\
\text { mean (SD) }\end{array}$ & $99.64(1.71)$ & $97.69(7.36)$ & $98.25(6.18)$ & $0.09^{\wedge}$ \\
\hline $\begin{array}{l}\text { Post injury Reported Health } \\
\text { mean (SD) }\end{array}$ & $60.79(26.79)$ & $70.44(25.25)$ & $69.04(25.44)$ & $0.03^{\wedge}$ \\
\hline GCS mean (SD) & $13.54(3.24)$ & $14.04(2.50)$ & 13.55 (3.05) & $0.27^{\wedge}$ \\
\hline ISS mean (SD) & $13.64(9.00)$ & $10.60(7.55)$ & $11.36(14.81)$ & $0.03^{\wedge}$ \\
\hline Length of stay mean (SD) & $17.29(27.16)$ & $16.66(27.71)$ & $20.68(34.77)$ & $0.89^{\wedge}$ \\
\hline ICU admission \% & 23.81 & 27.23 & 26.64 & $0.21 *$ \\
\hline Surgery \% & 9.52 & 6.93 & 7.38 & $0.56^{*}$ \\
\hline Head injury \% & 26.83 & 15.10 & 17.17 & $0.07^{*}$ \\
\hline Trauma team activation $\%$ & 28.57 & 19.80 & 21.31 & $0.20 *$ \\
\hline Seatbelt use \% & 4.88 & 12.24 & 10.97 & $0.17^{*}$ \\
\hline
\end{tabular}

The RTIs that involved a mobile phone were more severe than those not involving a mobile phone, as measured by the ISS (mean $=13.6$ vs. $10.6 ; p=0.03$ ). This pattern was also observed for self-reported health status on the day of the interview (60.8 vs. 70.4; $p=0.03$ ). Although the difference was not statistically significant, participants involved in mobile-phone related accidents were younger than participants who had accidents without mobile phone involvement (mean $=27.3 \mathrm{vs.} 31.7 ; p=0.12$ ). In addition, participants involved in mobile phone related accidents were more likely to be transported by an ambulance to the hospital than their counterparts $(82.9 \%$ vs. $63 \% ; p<0.05)$. Seatbelt use was much lower for participants involved in mobile phone-related accidents ( $4.8 \%$ vs. $12.2 \%)$, but the difference was not statistically significant $(p=0.1)$.

Overall, $71.3 \%$ of the cases reported moderate or severe disability in one of the five EQ-5D domains. Patients, who reported mobile phone involvement in RTIs, were more likely to suffer from "any disability" than patients without mobile phone involvement ( $83.3 \%$ vs. $68.8 \% ; p=0.05$, Table 2$)$. Notably, cases involved in mobile phone-related RTIs were more likely to report they had moderate or severe disability in mobility (71.4\% vs. $47.5 \%$; $p<0.01)$, self-care $(66.6 \%$ vs. $40.6 \%$; $p<0.00)$, and usual activities $(73.8 \%$ vs. $52.4 \% ; p<0.01$, Table 2$)$. Moderate to severe anxiety was also more prevalent in patients involved in accidents associated with mobile phone use, but the result was not significant ( $42.8 \%$ vs., $30.2, p=0.06)$.

Seatbelt compliance was low in both groups, especially among cases with RTIs associated with mobile phone use (4.8\%, Table 3). Among the controls, seatbelt compliance was $45.2 \%$ (95\% $C I=41.8-48.7)$ for highways and $23.8 \%(95 \% C I=21.2-26.7)$ for inner-city intersections. As for mobile phone use, the prevalence was higher among cases but statistically insignificant relative to controls $(17.2 \%$ vs. $13.8, p=0.1)$. For the controls, mobile phone use while driving was $15.1 \%$ (95\% $\mathrm{CI}=12.8-17.7)$ and $12.6 \%(95 \% \mathrm{CI}=10.6-15.0)$ at inner intersections. According to the regression analysis, using a mobile phone while driving is associated with 1.44 higher odds of sustaining a severe RTI (Table $4 ; p=0.04)$. 
Table 2. Frequencies of the five European Quality of Life (EQ-5D) dimensions by mobile phone use while driving.

\begin{tabular}{|c|c|c|c|}
\hline & Mobile Use & No Mobile Use & $p$-Value \\
\hline \multicolumn{4}{|c|}{ Mobility } \\
\hline No problem (\%) & $12(28.57)$ & $106(52.48)$ & \multirow{2}{*}{0.01} \\
\hline Moderate/Severe (\%) & $30(71.43)$ & $96(47.52)$ & \\
\hline \multicolumn{4}{|c|}{ Self-care } \\
\hline No problem (\%) & $14(33.33)$ & $120(59.41)$ & \multirow{2}{*}{$<0.01$} \\
\hline Moderate/Severe (\%) & $28(66.67)$ & $82(40.59)$ & \\
\hline \multicolumn{4}{|c|}{ Usual activities } \\
\hline No problem (\%) & $11(26.19)$ & $96(47.52)$ & \multirow{2}{*}{0.01} \\
\hline Moderate/Severe (\%) & $31(73.81)$ & $106(52.48)$ & \\
\hline \multicolumn{4}{|c|}{ Pain/discomfort } \\
\hline No problem (\%) & $22(52.38)$ & $113(55.94)$ & \multirow{2}{*}{0.67} \\
\hline Moderate/Severe (\%) & $20(47.62)$ & $89(44.06)$ & \\
\hline \multicolumn{4}{|c|}{ Anxiety } \\
\hline No problem $(\%)$ & $24(57.14)$ & $141(69.80)$ & \multirow{2}{*}{0.11} \\
\hline Moderate/Severe (\%) & $18(42.86)$ & $61(30.20)$ & \\
\hline \multicolumn{4}{|c|}{ Any disability } \\
\hline No problem $(\%)$ & $7(16.67)$ & $63(31.19)$ & \multirow{2}{*}{0.06} \\
\hline Moderate/Severe (\%) & $35(83.33)$ & $139(68.81)$ & \\
\hline
\end{tabular}

Table 3. Seatbelt use among cases and controls by mobile use status.

\begin{tabular}{cc}
\hline Group & Prevalence of Seatbelt Use \% (95\% CI) \\
\hline Cases (overall) & $9.0(6.2-12.9)$ \\
Mobile phone involvement & $4.8(1.1-18.4)$ \\
No mobile phone involvement & $12.2(8.3-17.6)$ \\
\hline Controls (overall) & $33.9(31.7-36.2)$ \\
Mobile phone involvement & $15.3(11.2-20.5)$ \\
No mobile phone involvement & $36.9(34.4-39.4)$ \\
\hline
\end{tabular}

Table 4. Logistic regression analyses of the association between mobile use and traffic injuries.

\begin{tabular}{ccc}
\hline Variables & $\begin{array}{c}\text { Logistic Regression of Odds of Traffic Injuries } \\
\text { Imputing Missing Values OR (95\% CI) }\end{array}$ & $p$-Value \\
\hline Mobile use & & \\
\hline Controls & Reference & 0.04 \\
\hline Cases & $1.44(1.00-2.05)$ & \\
\hline$N$ & 2018 & \\
\hline
\end{tabular}

\section{Discussion}

This study found mobile phone use while driving associated with RTIs increased the severity and prevalence of disability, and reduced HRQOL. We also found a high prevalence of seatbelt nonuse among both cases and controls. These findings highlight the need for behavioral public health interventions to reduce the impact of traffic violations on RTIs. Unless public health measures are 
initiated, mobile phone-related RTIs are likely to continue to have a significant effect on the population health of SA.

Our estimate is lower than reported in literature from countries such as the United States (US), which suggests that mobile phone use while driving is associated with a fourfold increased risk of RTIs [31]. McEvoy et al. reported a similar finding in the United Kingdom (UK), where a fourfold increased risk of RTIs was reported for both hand-held and hands-free devices [16]. It is possible that patients included in our study underreported mobile phone use. Performing a sensitivity analysis, assuming that participants with missing values (22\%) were involved in mobile phone-related RTIs, the estimated impact of mobile phone use on RTIs was similar to what has been reported in the US and the $\mathrm{UK}(\mathrm{OR}=3.5 ; 95 \% \mathrm{CI}=2.6-4.5)$.

The prevalence of mobile phone use in the control group is also higher than in other countries. Based on different observational studies, $2.8 \%$ of drivers in Canada, $7 \%$ of drivers in the US, and $2.2 \%$ of drivers in the UK are using a mobile phone while driving [32-34]. However, some literature highlights a different pattern. In Australia, the prevalence of texting or browsing on phones while driving was approximately $50 \%$ for drivers [35]. In the Ukraine, $22.2 \%$ of drivers reported using their phones on a daily bases for texting or reading text messages [36]. Both studies collected self-reported habitual use data, a different approach than the method used in the current study which may explain the significant differences.

Several previous studies investigated mobile phone use of SA drivers [22,23]. Using a self-report questionnaire in the general population, Osuagwu et al. estimated that mobile phone use was associated with a seven times higher likelihood of accidents [24]. Another study in a neighboring country, Oman, reported $90 \%$ mobile phone use while driving [37]. It is not possible to compare our findings directly to previous studies due to the differences in methodology. An essential contribution of the current study is that the association between mobile phone use and traffic accidents was not estimated, the study focused on RTIs, which has more implications for population health.

As expected, younger individuals were more likely to incur mobile phone-related RTIs. In addition, we found mobile phone use to be associated with disability in three of the five EQ-5D domains. The likelihood that RTIs in a younger population will result in disabilities leading to a lifelong impact on population health is high. A previous study in SA with young trauma patients, mostly due to RTIs, found that one-third suffered permanent disabilities [38]. The impact of RTIs on a younger population is an essential consideration for public health officials as well as the traffic police to design prevention programs suitable for this group. Specifically as using a mobile phone while driving is considered a traffic violation in SA [39].

Because using a phone while driving is a traffic violation, it is fair to say that the driver was at fault in the crash. This may not always be the case. Literature does suggest, however, that mobile phone use while driving decreases response time and awareness of surroundings [40].

The use of social media applications has become increasingly popular in SA, which may underpin the behavior of driving and mobile phone usage. According to the Communications and Information Technology Commission (CITC), 91.7\% of the population is using social media [41]. Literature suggests there are different levels of distractions, and different risks may be associated with various activities [33]. Additional research is required to understand exactly what injured drivers were doing while using the mobile phone (i.e., Snapchat, texting, etc.). Knowing the specific use of social media applications may guide prevention strategies to design practical approaches to promote safety, for example, partnering with social media applications to disseminate safety messages.

The present study has several implications for public health practice and policy. Firstly, the results can assist safety advocates to educate the public, policymakers, and clinicians about the dangers of using mobile phones while driving. Secondly, public health prevention programs by governmental agencies may use these results as a baseline to evaluate the effectiveness of existing and future interventions to reduce traffic violations. Traffic Police also should use this finding to guide and intensify enforcement efforts. Similar to the Healthy People 2020 program in the US, SA has 
launched the Saudi Vision 2030 [42]. One of the many goals of this vision is reducing the burden of RTIs. Therefore, the Saudi Vision 2030 can use our results as a baseline to monitor improved compliance in response to interventions to pave the way to improve traffic safety.

Despite existing laws, our study found a low prevalence of seatbelt use among both cases and controls (10\% and 33\%, respectively). Moreover, population-level estimates suggest seatbelt compliance is as low as $5 \%$ in SA though it is one of the most effective and cheapest interventions to reduce RTIs $[23,43]$. Estimates from studies in developed countries indicate that persons not wearing a seatbelt at the time of the injury are 5.4 times more likely to die, 1.9 times more likely to be hospitalized, and cost $\$ 268,000$ more than individuals wearing seatbelts [44]. Unfortunately, seatbelt use remains a neglected issue, which may explain the low compliance rate compared to other developed countries. There is an urgent need to take a serious stand to increase compliance nationwide.

Due to the significant burden of RTIs, the Traffic Police has implemented a few initiatives to support traffic safety. The most significant of which have been mandating seatbelt use in 2001, introducing speed cameras in 2010, and launching mobile phone and seatbelt use detection cameras in March 2018 [39]. Future studies are required to evaluate the effectiveness of this new technology in reducing seatbelt and mobile phone violations.

Our study has several important limitations which must to be acknowledged. Firstly, because cases were obtained from a single hospital, generalizing the findings to SA is problematic. Secondly, information bias may be a threat to the validity of our study because the use of seatbelt and mobile phone in the cases were self-reported. Over $22 \%$ of the interviewed patients reported they do not know or remember whether a mobile phone was involved in the accident. It is possible that these patients chose not to report mobile phone use due to social desirability bias, fear of citation, or other legal repercussions. Thirdly, due to the nature of selecting controls, we were unable to adjust for several variables, for example age, that may act as potential confounders. In addition, the accuracy of documenting seatbelt and mobile phone use for passing vehicles, especially in highways, will likely depend on the vehicle's speed, weather conditions, or even the observer's ability (i.e., eyesight). Despite that, there was high agreement between observers in our study reducing the likelihood of bias. It should be noted that despite finding an association in the regression analysis, our results may underestimate the effects of mobile phone use while driving on RTIs. One reason is that our study was limited to nonfatal injuries. Nearly $9 \%$ of traffic accident victims die either before or after reaching healthcare facilities in SA [45]. We excluded patients who died because it was not possible to obtain accurate data about the actual use of a mobile phone from the deceased drivers. In addition, we excluded possible participants intubated for more than two weeks. These two exclusions may have caused an underestimation of the impact of mobile phone use on RTIs. Future studies should aim to incorporate records from phone companies to negate this limitation. Finally, the classification of mobile phone-related accidents was only done for the injured driver or passenger. The possibility exists that the other driver involved in the accident caused the accident due to being distracted by a mobile phone. Such a case was not captured in the current study and may have led to underestimating the impact of mobile phone use on RTIs.

Nevertheless, this study has numerous strengths. Firstly, by observing drivers on Riyadh roads, we used a more representative approach to select controls which increase the likelihood to represent the underlying population. Secondly, the use of a large number of controls improved the power of the study. Thirdly, the ability to abstract data from medical records allowed examining not only the association between mobile phone use and motor vehicle accidents but also the impact on injury severity and healthcare utilization. Finally, we used a sound statistical approach to manage missing values taking uncertainty into account.

\section{Conclusions}

In summary, we found mobile phone use while driving to be associated with RTIs, an increased severity and higher prevalence of disability, and a reduction in the HRQOL. This result emphasizes an 
alarming concern, namely that using a mobile phone while driving is a significant threat to traffic safety and population health in SA. Seatbelt use remains extremely low compared to developed nations and requires significant improvement. Prevention programs may use these results to educate the public, advocate for increased enforcement, and to raise investment in public health programs to reduce RTIs and improve the Saudi Arabian population's health.

Author Contributions: Data curation, J.T., A.A., M.A. (Mohamed Alrowaily), F.A. and I.A.; formal analysis, S.A.; funding acquisition, M.A. (Mohamed Alkelya); methodology, M.A. (Mohamed Alkelya); project administration, F.A. and I.A.; resources, M.A. (Mohamed Alrowaily); supervision, S.A., M.A. (Mohamed Alkelya) and I.A.; validation, M.A. (Mohamed Alkelya); writing_original draft, S.A., J.T., A.A. and M.A. (Mohamed Alrowaily); and writing - review and editing, S.A., J.T., A.A. and F.A.

Funding: The study was funded by King Abdulah International Medical Research Center (KAIMRC) RC16/177/R.

Acknowledgments: The authors would like to thank Susanna Wright for help in editing this manuscript.

Conflicts of Interest: The authors declare no conflict of interest. The funders had no role in the design of the study; in the collection, analyses, or interpretation of data; in the writing of the manuscript, or in the decision to publish the results.

\section{References}

1. Peden, M. World Report on Road Traffic Injury Prevention: Summary; World Health Organization: Geneva, Switzerland, 2004; Available online: http://www.who.int/violence_injury_prevention/publications/road_ traffic/world_report/summary_en_rev.pdf (accessed on 25 July 2019).

2. Dalal, K.; Lin, Z.; Gifford, M.; Svanström, L. Economics of Global Burden of Road Traffic Injuries and Their Relationship with Health System Variables. Int. J. Prev. Med. 2013, 4, 1442-1450.

3. Memish, Z.A.; Jaber, S.; Mokdad, A.H.; AlMazroa, M.A.; Murray, C.J.; Rabeeah, A.A. Burden of disease, injuries, and risk factors in the Kingdom of Saudi Arabia, 1990-2010. Prev. Chronic. Dis. 2014, 11, E169. [CrossRef]

4. Chan, M. The Global Status Report on Road Safety 2013. Geneva. 2013. Available online: http://www.who.int/violence\%7B_\%7Dinjury\%7B_\%7Dprevention/road\%7B_\%7Dsafety\%7B_ \%7Dstatus/2013/report/en/index.html (accessed on 25 July 2019).

5. Mansuri, F.A.; Zalabani, A.H.; Zalat, M.M.; Qabshawi, R.I. Road safety and road traffic accidents in Saudi Arabia: A systematic review of existing evidence. Saudi Med. J. Int. 2015, 36, 418-424. Available online: http://www.ncbi.nlm.nih.gov/pmc/articles/PMC4404474/ (accessed on 25 July 2019).

6. Ansari, S.; Akhdar, F.; Mandoorah, M.; Moutaery, K. Causes and effects of road traffic accidents in Saudi Arabia. Public Health 2000, 114, 37-39. [CrossRef]

7. Dawam, H. Traffic Accidents Statistics in Saudi Arabia. 2016. Available online: https://ksa.motory.com/ar/ الاخبار / إحصائياتا لحوادثفيالسعودية لعام-143 (accessed on 25 July 2019).

8. Jamshidi, E.; Moradi, A.; Majdzadeh, R. Environmental risk factors contributing to traffic accidents in children: A case-control study. Int. J. Inj. Contr. Saf. Promot. 2016, 7300, 1-7. [CrossRef] [PubMed]

9. Hijar, M.; Carrillo, C.; Flores, M.; Anaya, R.; Lopez, V. Risk factors in highway traffic accidents: A case control study. Accid. Anal. Prev. 2000, 32, 703-709. [CrossRef]

10. Islam, M.; Kanitpong, K. Identification of factors in Road ACCIDENTS Through in-depth Accident Analysis. IATSS Res. Int. 2008, 32, 58-67. [CrossRef]

11. Jafarpour, S.; Rahimi-Movaghar, V. Determinants of risky driving behavior: A narrative review. Med. J. Islam. Repub. Iran Int. 2014, 28, 142.

12. Lee, V.K.; Champagne, C.R.; Francescutti, L.H. Fatal distraction: Cell phone use while driving. Can. Fam. Physician 2013, 59, 723-725.

13. Ranney, T.A.; Garrott, W.R.; Goodman, M.J. Nhtsa Driver Distraction Research: PAST, PRESENT, AND FUTURE Internet. Available online: https://www.sae.org/publications/technical-papers/content/2001-060177/ (accessed on 30 June 2019).

14. WHO. Mobile Phone use: A Growing Problem of Driver Distraction. In World Health Organization Report; World Health Organization: Geneva, Switzerland, 2011.

15. Asbridge, M.; Brubacher, J.R.; Chan, H. Cell phone use and traffic crash risk: A culpability analysis. Int. J. Epidemiol. 2013, 42, 259-267. [CrossRef] 
16. McEvoy, S.P.; Stevenson, M.R.; McCartt, A.T.; Woodward, M.; Haworth, C.; Palamara, P. Role of mobile phones in motor vehicle crashes resulting in hospital attendance: A case-crossover study. BMJ Br. Med. J. 2005, 331, 428. [CrossRef] [PubMed]

17. Redelmeier, D.; Tibshirani, R.J. Association between cellular telephone calls and motor vehicle collisions. N. Eng. J. Med. 1997, 336, 453-458. [CrossRef]

18. Knapper, A.S.; Hagenzieker, M.P.; Brookhuis, K.A. Do in-car devices affect experienced users' driving performance? IATSS Res. 2015, 39, 72-78. [CrossRef]

19. ICT Indicators Charts End of Q4 2014. Available online: https://www.citc.gov.sa/en/indicators/Pages/archive. aspx (accessed on 22 September 2018).

20. Road Traffic Injuries Internet; World Health Organization: Geneva, Switzerland, 2015. Available online: http://www.who.int/mediacentre/factsheets/fs358/en/ (accessed on 25 July 2019).

21. Hassan, M.H. Examining Factors Associated with Involvement of Saudi Young Drivers in At-fault Crashes: Survey-Based Study. 2014. Available online: https://www.researchgate.net/publication/280136155_ Examining_the_factors_associated_with_the_involvement_of_the_Saudi\%27_young_drivers_in_at-fault_ crashes_A_Survey-Based_Study (accessed on 25 July 2019).

22. Jawadi, A.H.; Alolayan, L.I.; Alsumai, T.S.; Aljawadi, M.H.; Philip, W.; Alharthy, N.A. Seat Belt Usage and Distracted Driving Behaviors in Saudi Arabia: Health-care Providers versus Nonhealth-care Providers. J. Musculoskelet. Surg. Res. 2017, 1, 10-15. [CrossRef]

23. Bcheraoui, C.; Basulaiman, M.; Tuffaha, M.; Daoud, F.; Robinson, M.; Jaber, S. Get a License, Buckle Up, and Slow Down: Risky Driving Patterns Among Saudis. Traffic Inj. Prev. 2015, 16, 587-592. [CrossRef]

24. Osuagwu, U.; Osuagwu, M.; Bam, D.K.C.O. Assessing the Effects of Mobile Phone Use Test Messages and Chatting On Social Media among Saudi and Non-Saudi Drivers. Int. J. Appl. Sci. Technol. 2013, 3, $107-117$.

25. Alghnam, S.; Alkelya, M.; Alfraidy, M.; Al-Bedah, K.; Albabtain, I.T.I.T.; Alshenqeety, O. Outcomes of road traffic injuries before and after the implementation of a camera ticketing system: A retrospective study from a large trauma center in Saudi Arabia. Ann. Saudi Med. 2017, 37, 1-9. [CrossRef]

26. Barrimah, I.; Midhet, F.; Sharaf, F. Epidemiology of road traffic injuries in qassim region, saudi arabia: Consistency of police and health data. Int. J. Health Sci. (Qassim) 2012, 6, 31-41. [CrossRef]

27. Alghnam, S.; Alrowaily, M.; Alkelya, M.; Alsaif, A.; Almoaiqel, F.; Aldegheishem, A. The prevalence of seatbelt and mobile phone use among drivers in Riyadh, Saudi Arabia: An observational study. J. Saf. Res. 2018, 66, 33-37. [CrossRef]

28. Derrett, S.; Black, J.; Herbison, G.P. Outcome after injury-a systematic literature search of studies using the EQ-5D. J. Trauma. 2009, 67, 883-890. [CrossRef]

29. Aburuz, S.; Bulatova, N.; Twalbeh, M.; Gazawi, M. The validity and reliability of the Arabic version of the EQ-5D: A study from Jordan. Ann. Saudi Med. 2009, 29, 304-308. [CrossRef]

30. Khoudri, I.; Belayachi, J.; Dendane, T.; Abidi, K.; Madani, N.; Zekraoui, A. Measuring quality of life after intensive care using the Arabic version for Morocco of the EuroQol 5 Dimensions. BMC Res. Notes 2012, 5, 56. [CrossRef] [PubMed]

31. Ouimet, M.C.; Lee, S.E.; Dingus, T.A. Distracted Driving and Risk of Road Crashes among Novice and Experienced Drivers. N. Eng. J. Med. 2014, 370, 54-59.

32. Burns, P.; Lécuyer, J.F.; Chouinard, A.; Canada, T. Observed Driver Phone Use Rates in Canada. Proc. Can. Multidiscip. Road Saf. Conf. 2008, 8-11.

33. Sullman, M.J.M. An observational study of driver distraction in England. Trans. Res. Part F Traffic Psychol. Behav. 2012, 15, 272-278. [CrossRef]

34. Wenners, K.; Knodler, M.; Kennedy, J.; Fitzpatrick, C. Large-Scale Observational Study of Drivers' Cell Phone Use. Trans. Res. Rec. J. Trans. Res. Board 2013, 2365, 49-57. [CrossRef]

35. Oviedo-Trespalacios, O.; King, M.; Haque, M.M.; Washington, S. Risk factors of mobile phone use while driving in Queensland: Prevalence, attitudes, crash risk perception, and task-management strategies. PLoS ONE 2017. [CrossRef] [PubMed]

36. Hill, T.; Sullman, M.J.M.; Stephens, A.N. Mobile phone involvement, beliefs, and texting while driving in Ukraine. Accid. Anal. Prev. 2019. [CrossRef] [PubMed]

37. Reesi, H.; Maniri, A.; Plankermann, K.; Hinai, M.; Adawi, S.; Davey, J. Risky driving behavior among university students and staff in the Sultanate of Oman. Accid. Anal. Prev. 2013, 58, 1-9. [CrossRef] [PubMed] 
38. Alghnam, S.; AlSayyari, A.; Albabtain, I.; Aldebasi, B.; Alkelya, M. Long-term disabilities after traumatic head injury (THI): A retrospective analysis from a large level-I trauma center in Saudi Arabia. Inj. Epidemiol. 2017, 4, 29. [CrossRef]

39. MOI. Traffic Violations in Saudi Arabia; Department of Traffic: Riyadh, Saudi Arabia, 2017.

40. Consiglio, W.; Driscoll, P.; Witte, M.; Berg, W.P. Effect of cellular telephone conversations and other potential interference on reaction time in a braking response. Accid. Anal. Prev. 2003, 35, 495-500. [CrossRef]

41. Mohamed, I. Social Media Usage in Saudi Arabia at Its Peak: CITC; Saudi Gazette: Jeddah, Saudi Arabia, 2019; Available online: http://saudigazette.com.sa/article/562919/SAUDI-ARABIA/Social-media-usage-in-SaudiArabia-at-its-peak-CITC (accessed on 29 July 2019).

42. Government of Saudi Arabia. Saudi Arabia Vision 2030; Government of Saudi Arabia: Riyadh, Saudi Arabia, 2016.

43. Carpenter, C.S. The Effects of Mandatory Seatbelt Laws on Seatbelt Use, Motor Vehicle Fatalities, and Crash-Related Injuries among Youths. J. Health Econ. 2007, 27, 642-662. [CrossRef] [PubMed]

44. Bigelow, W. Non-seatbelt use for motor vehicle crashes in Wisconsin, Madison. 2010. Available online: https://www.chsra.wisc.edu/codes/special-cost/seatbelt-use-outcomes-2010.pdf (accessed on 25 July 2019).

45. Alghnam, S.; Alkelya, M.; Al-Bedah, K.; Al-Enazi, S. Burden of traumatic injuries in Saudi Arabia: lessons from a major trauma registry in Riyadh, Saudi Arabia. Ann. Saudi Med. 2014, 34, 291-296. [CrossRef] [PubMed]

(C) 2019 by the authors. Licensee MDPI, Basel, Switzerland. This article is an open access article distributed under the terms and conditions of the Creative Commons Attribution (CC BY) license (http://creativecommons.org/licenses/by/4.0/). 